\title{
Financial and measured quality performance currently don't go hand-in-hand in Flemish non-university hospitals.
}

\author{
Werner Jacobs MD, MBA, University Hospital Antwerp, University of Antwerp and Antwerp \\ Management School, Belgium
}

Geert Scheipers, RC, Antwerp Management School and Delaware Consulting, Belgium

\begin{abstract}
The value paradigm in healthcare emphasises on financial rewarding of higher quality of care at lower cost. We evaluated the financial and quality performance of all 52 Flemish (Belgium) non-university, general hospitals using 2 publicly available databases. The financial situation of many Flemish hospitals is precarious. In the observation period 2012-14, one in four hospitals had a negative profit and half of the hospitals had a net profit of less than 1 million euro. Average profitability of all hospitals was $0.9 \%$ (SD 1.4\%). Measured and published quality of care in Flemish general hospitals is highly variable and ranges from 'fairly poor' to 'rather well'. Accredited and larger hospitals demonstrate a higher level of measured quality performance than others. No correlation could be found between financial performance or investments and the delivery of measured quality of care. We conclude that, to date, financial and quality performance don't go hand-in-hand in Flemish non-university hospitals. Quality of care is currently no guarantee for financial health and vice versa. Policy implication: implementing a value-driven financing model will remain a major challenge for Flemish hospitals. Longitudinal follow-up is however desirable to determine a possible gap period between quality of care improvement (patient value) and hospital financial reward.
\end{abstract}




\section{Synopsis}

\section{Purpose}

The purpose of this study is to evaluate the current financial and measured/published quality status of all 52 Flemish (Belgium), non-university general hospitals and to see whether a correlation exists between a hospital's financial performance and its measured and published quality performance. Do higher standards of measured/published quality result in better financial performance in Flemish, non-university, general hospitals or do financially better performing hospitals deliver higher quality standards of care?

\section{Problem of practice}

To fulfil their missions and meet the value expectations of healthcare stakeholders, hospitals need to be financially healthy and deliver demonstrable standards of high quality. Achieving good patient health outcomes are the key measure of quality in healthcare (Porter, 2010). Quality performance needs to be measured and made public to stimulate improvement activities and hence create added value (Hibbard, Stockard, \& Tusler, 2003). Hospitals engaged in both public reporting and pay for performance achieve modestly greater improvements in quality than do hospitals engaged only in public reporting (Lindenauer et al., 2007).

Flemish general hospitals have only recently engaged in measuring their quality of care and making this information publicly available (VIP ${ }^{2}$ project). But increasing national healthcare expenditure in Belgium puts financial restraints on hospitals. The 'Budget Financial Means' does no longer suffice to operate a hospital and hospitals seek additional income via volume-driven medical (over)consumption to break even. To illustrate, the average day price for birth delivery (1- 
person room) in 2014 was 1,184 euro in Flanders, 1,832 euro in Wallonia, and 2,297 euro in the Brussels capital area. The current hospital financing model in Belgium (and thus also in Flanders) leaves room for dysfunctional behaviour: stimulating medical overconsumption that leads to a derailment of national healthcare expenditure just to keep hospitals financially viable. Healthcare researchers start to agree that the way to disrupt this vicious cycle is a value-driven (financing) system in which outcomes are measured around medical conditions (and not around medical specialties or interventions) and what matters to patients. The payment approach best aligned with "value" is a bundled payment based on those outcomes, knowledge of efficient processes, and costs incurred over an entire cycle of care (Porter \& Lee, 2013). Porter \& Lee (2013) describe that such an approach helped a German hospital to keep average payment for a hospitalization below $\$ 5,000$ compared with more than $\$ 19,000$ in the U.S.. However, the million dollar question amongst many hospital administrators is still whether it is feasible to make a shift in hospital financing from a volume-driven towards value-driven model while assuring the going concern of their organizations.

\section{Results}

Financial performance. Analysis of the financial data of all 52 general hospitals in Flanders (period 2012-14) shows that one in four hospitals is not in a financially healthy state. If we consider a hospital to be healthy when 1) revenues and expenses are in balance, 2) adequate resources (capital) are available to deliver services and finance operations in both short and long term, and 3) the hospital must be able to replenish or renew itself, then many of the Flemish hospitals are in a precarious financial situation. Average profitability of the hospitals in our study is only $0.9 \%$ (SD 1.4\%). One in four hospitals has a negative 3-year average profit. Liquidity is for most (50/52) hospitals acceptable but solvability is more problematic for $30 \%$ of the hospitals. 
Many hospitals however continue to invest in medical infrastructure. Net profit and liquidity performance relate to the number of hospital beds.

Quality of care. Measured and published quality of care for these hospitals ranges from 'fairly poor' (scoring 0-3 times above Flemish average on 19 scoring items) to 'rather well' (scoring 12 to 15 times above average). There are currently in Flanders no general hospitals with perfect quality scores. Accredited hospitals (currently only 5 out of 52 Flemish non-university hospitals) and larger hospitals score significantly better on measured quality of care.

At this time, there is no correlation between financial performance or investments and measured/published quality of care in Flemish non-university general hospitals. There are hospitals with excellent financial performance but without demonstrable quality of care measurements as well as hospitals demonstrating good quality performance but that are in poor financial state.

\section{Conclusions}

The financial performance of many general hospitals in Flanders is worrisome to say the least. Practices of measuring and publishing quality performance are for many hospitals still in an embryonal stage although some hospitals are trying to take the lead in this international trend (Pollock, 2008) (Albright \& Feeley, 2011) (Porter \& Guth, 2012). Today, financial and measured/published quality performance don't go hand-in-hand in Flemish hospitals. High quality of care is no guarantee for financial health and vice versa. Longitudinal follow-up is however desirable.

\section{Practical relevance}

For Flemish hospitals, aligning government spending on healthcare with value for patients in terms of patient's health over time might not become as easy as the theoretical model (Porter, 
2009) (Lee, 2010) suggests. In Belgium, an historic financing system that rewards interventions rather than outcomes perversely stimulates medical overconsumption and in addition allows hospitals to survive financially since such incomes are needed to cover an insufficient basic financing (so-called "Budget Financial Means") needed to operate a hospital. Nevertheless, an onset is given by the current Belgian Minister of Health towards incentivising quality of care. In her policy plan, Minister Maggie De Block stated: "The government and hospitals will also have to work with a new financing system. That has to lead to a correct financing of accountable care and it must encourage both efficiency and quality improvement". Success stories have been published (Pollock, 2008) (Albright \& Feeley, 2011).

\section{Keywords}

hospitals, performance, financial, quality, outcome, Flanders, healthcare, value.

\section{Methods}

\section{Research question}

RQ1: What is the current financial and measured/published quality performance status of Flemish, non-university, general hospitals?

RQ2: Is there a correlation between financial performance or medical investments and quality performance in Flemish, non-university, general hospitals?

\section{Method \& design}


A quantitative study that makes use of 2 publicly available data sets. We conduct a comparative and correlational study using published financial/investment and self-reported quality data from all Flemish general hospitals.

\section{Sample Size}

All 52 Flemish non-university, general hospitals.

\section{Data Collection Strategy}

Financial data of all 52 hospitals were obtained from the annual Belfius-MAHA study. Five financial parameters are used: profitability, solvability, liquidity, continuity, and net profit. Quality data were obtained from the website www.zorgkwaliteit.be, a public forum initiated by the Flemish Government ('Vlaams Indicatorenproject voor Patiënten en Professionals - VIP's') in collaboration with the healthcare sector ('Vlaanderen in Zorg'). Quality, as a multifaceted construct, is currently scored and reported on 3 dimensions: breast cancer care, patient satisfaction, and hospital-wide and it is for many Flemish hospitals still in a start-up phase. New dimensions will be added in the next

coming years. We also assessed the hospital's accreditation status and whether hospitals participated in regional or international community work.

\section{Analysis of the problem}

\section{Practical Problem}

Healthcare industry has survived economically by cross-subsidizing margin shortfalls in one activity with revenues generated by others. The very existence of these cross-subsidies is symptomatic of deep flaws in the healthcare reimbursement system and is leading to a derailment 
of healthcare expenditure in western society. There is thus a need for an 'intelligent redesign' of healthcare delivery and the way it is financed. A value-driven system is needed, and such a system is based on knowledge of efficient processes and costs incurred over an entire cycle of care and it will (financially) reward healthcare organizations for delivering higher quality care at lower cost (demand and patient approach) instead of merely financing medical consumption (supply and provider approach). Embracing the goal of value at the senior management level is essential, because the value agenda requires a fundamental departure from the past (Porter \& Lee, 2013). Policy makers have also started to emphasize on linking payment and quality. 'Accountable Care Organizations' are those hospitals that are characterized by a payment and care delivery model that seeks to tie provider reimbursements to quality metrics and reductions in total cost (Shortell \& Casalino, 2008). Hospitals need to be financially healthy and provide high quality of care to face these new challenges in healthcare.

Flemish hospitals are financed from 3 sources: 'Budget Financial Means' (a flat government allowance per hospitalized patient), a pay-for-medical performances and fixed allowances for socalled 'conventions', and fixed pharmacy financing. This method of hospital financing however has aberrant side-effects: it stimulates medical overconsumption to keep Belgian/Flemish hospitals financially viable. Not surprisingly, Belgian public healthcare expenditure is significantly higher than OECD average (in 2013, 8\% of GDP vs. 6,5\%) (http:/www.oecd.org/els/healthsystems/health-expenditure.htm). New methods for hospital financing are not surprisingly on the political agenda. In her policy plan, Belgian Minister of Health Maggie De Block made an onset for a new hospital financing model that becomes more value-driven: "The government and hospitals will also have to work with a new financing system. That has to lead to a correct financing of accountable care and it must encourage both efficiency and quality improvement". How will 
hospital administrators embrace and deal with this value paradigm is currently an important question in hospital governance and management. Therefor we need to have a clear view of the current (and future) financial and quality status of our general hospitals.

\section{Literature Review}

In corporations, profitability and share value constitute important criteria to assess strategic decisions made by management. In hospitals, the objectives are less unequivocal and often contradictory (Eeckloo et al., 2004). The main objective of hospitals is to provide qualitative, specialised care. But next to this, hospitals must pay attention to the accessibility of their care and the financial equilibrium of the hospital's exploitation. Hospitals are evolving from supply and provider driven organizations to demand and patient driven institutions (Eeckloo et al., 2004) (Porter \& Lee, 2013). At its core should be maximizing value for patients (Porter, 2010) whereby patient "value" is defined as "the health outcome achieved that matters to the patients relative to the cost of achieving these outcomes" (Porter \& Lee, 2013). The main proposition is that this notion of value constitutes the only goal that can unite the interests of all system participants. Value management in healthcare starts from measuring and communicating outcomes that matter to patients and relate this to the cost of care over the patient care cycle (Porter \& Lee, 2013). In most U.S. and European countries the dominant payment model is based on a fee-for-service logic (Porter \& Kaplan, 2016). This implies that volume (number of clinical acts) is the key financial driver for healthcare providers. The focus in value-based care delivery is on Care (improve), Health (improve), and Cost (reduce) (Berwick, 2008). Measuring value will permit reform of the reimbursement system so that it rewards value by providing bundled payments covering the full care cycle. Aligning reimbursement with value in this way rewards providers for efficiency in achieving good outcomes while creating accountability for substandard care (Porter, 2010). Neither 
of the classic payment models in healthcare directly rewards improving the value of care nor makes them accountable for patient level value. Recently value-driven instead of volume-based hospital financing is becoming more and more the new standard (Miller, 2009) and is already practised by hospitals such as the Cleveland Clinic, the Mayo Clinic, and Virginia Mason. In contrast to the classic volume-driven hospital financing mechanisms, in a value-driven model outcomes that matter to the patient are incentivised and bundled payments for a full cycle of care are installed (Porter \& Lee, 2013). In surgery, such bundled payments for a full cycle of care could result in significant savings (Miller, 2011).

The challenges of understanding non-profit organizational performance have been addressed in more detail by Herman and Renz (Herman \& Renz, 1999) and Forbes (Forbes, 1998). In the hospital setting, cash flow, asset turnover, mortality, complications, length of inpatient stay, cost per case, and percent of revenue from outpatient care are a good set of parameters to measure hospital performance (Griffith et al., 2002). Robust financial performance however is not associated with improved publicly reported outcomes for common hospital conditions such as acute myocardial infarction, congestive heart failure and pneumonia (Nguyen, Halm, \& Makam, 2016). Reassuringly, improved mortality and readmission rates did not necessarily lead to loss of revenue in this study. When a hospital makes more profit, has a capacity to finance investments using debt and pays higher wages, its quality of care would generally improve (Dong, 2015). Quality positively influences hospital financial performance in for-profit hospitals (Vélez-Gonzalez, Pradhan \& Weech-Maldonado, 2011).

The new healthcare value paradigm puts more and more emphasis on delivering measurable quality standards to the patient and other stakeholders and such publicly made available performance measures will most likely become the future measure of hospital performance. 
Publication of performance data has been associated with improvement of health outcomes despite physician scepticism (Marshall et al., 2000). Hospitals engaged in both public reporting and pay for performance achieve greater improvements in quality than did hospitals engaged in public reporting only (Lindenauer et al., 2007). Signatures of high-performing hospitals include hospital boards that pay greater attention to clinical quality with a hospital management that better monitored quality performance and boards that used clinical quality metrics more effectively (Tsai et al., 2015).

Several significant limitations to measuring performance in non-profit organizations exist. For one, the non-profit status itself limits judgemental options of relying strictly on financial performance indicators. Many authors agree that for non-profit organisations, performance could be evaluated using a reasonable set of criteria/parameters of which some reflect the organizations vision and mission (Brown, 2005) and others the benefits for the non-profit organisation's stakeholders.

\section{Findings}

\section{Financial performance of Flemish non-university hospitals}

Profitability: can the hospital run its business with its annual revenues? We divide net profit by total revenue. Net profit includes the operating income and the financial result. A negative figure means loss; a margin of $0-1 \%$ of the revenue means that a small financial mishap can push the hospital into financial loss.

The 3-year average profitability of all Flemish hospitals was $0.9 \%$ (SD 1.4\%). The range varied from $-2 \%$ to $5.9 \%$. Only 23 of the 52 hospitals $(44,2 \%)$ had a 3 -year average profitability above the $1 \%$ reference point. In 2014,1 hospital had a profitability between [5-6\%] and one 
hospital had a negative profitability of more than $-4 \%$. The best 5 hospitals scored between [3.8$5.9 \%$ ], the worst 5 hospitals scored between [minus $0.9-4.1 \%$ ]. When comparing the number of hospital beds for the 10 best $(685+/-533)$ and 10 worst $(345+/-228)$ performing hospitals, there was a tendency that better performing hospitals had more hospital beds, but the difference was not significant $(\mathrm{p}=0.08)$.

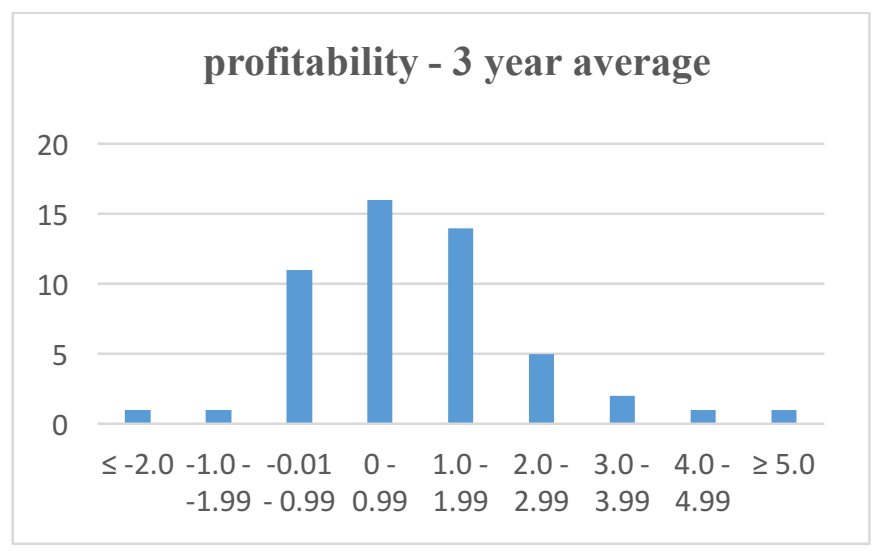

Net profit. The 3-year average net profit of all Flemish hospitals was 1.6 million euro (SD 3.0 million euro). The range varied from -1 million to 19.3 million euro. Thirteen of the 52 hospitals (25\%) had a negative 3-year average profit. In 2014, 1 hospital outperformed with a net profit of 25.2 million euro. Profit of the 5 best performing hospitals varied between 5.0 and 25.2 million euro; profit of the 5 worst performing hospitals varied between minus 0.6 and minus 1.6 million euro. Ten hospitals (19.2\%) had in 2014 a negative profit (20 in 2013, 13 in 2012). Half of the hospitals had a profit above 1 million euro in 2014. When comparing the number of hospital beds for the 10 best $(763+/-517)$ and 10 worst $(349+/-226)$ performing hospitals, there is a significant difference: better performing hospitals have more hospital beds $(p=0.03)$. 


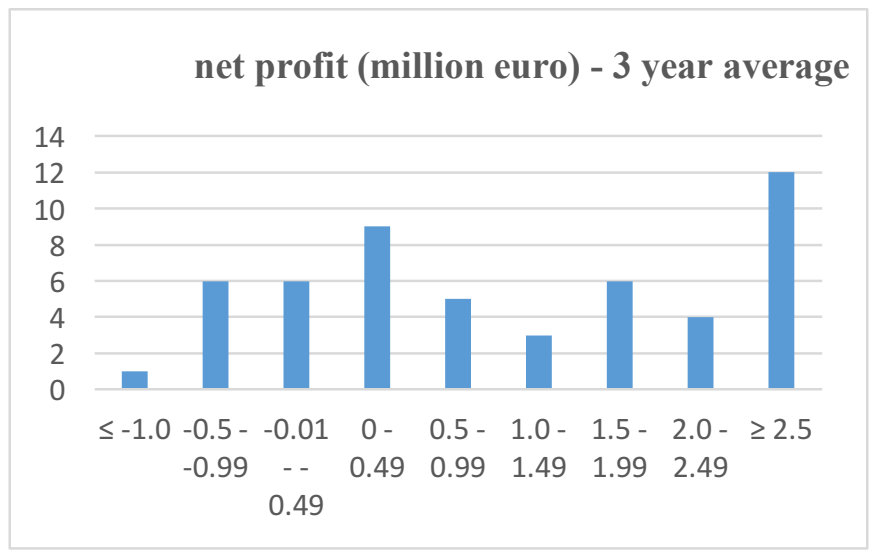

Solvability. How solid is the hospital? We take hospital equity without government support for investments and divide this by the balance total of assets/liabilities. According to Belfius, a financially healthy hospital should have a hospital equity of $20 \%$ of the balance total of assets/liabilities.

The 3-year average solvability of all Flemish hospitals was $27.8 \%$ (SD 13.0\%). The range varied from $3.3 \%$ to $69.3 \%$. Thirty seven (of 52 ) hospitals $(71.1 \%)$ were above the cut-off value of 20\%. In 2014, 1 hospital had a solvability between [60-70\%] and 1 hospital scored between [50$60 \%$ ]. Tree hospitals had a solvability lower than $10 \%$. The best 5 hospitals scored between [47$69 \%$ ]; the worst 5 hospitals between [3-13\%]. There is no statistical difference in the number of hospital beds of the 10 best versus 10 worst performing hospitals.

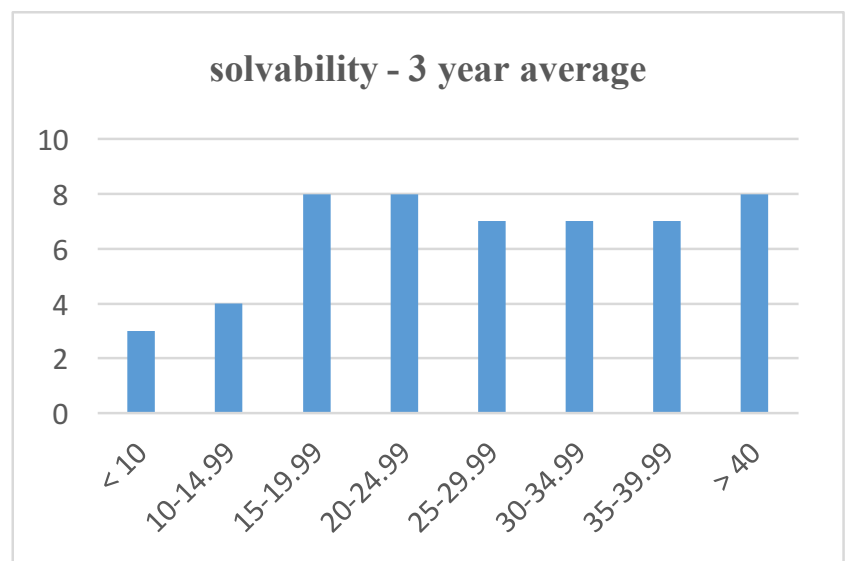


Liquidity. Is there a danger that the hospital might encounter cash flow problems? We compare short term assets that can be sold against short term debts. According to Belfius, this ratio should be higher than 1 .

The 3-year average liquidity of all Flemish hospitals was 2,0 \% (SD 1,0\%). The range varied from $1.0 \%$ to $6.7 \%$. Only 2 hospitals had a liquidity ratio of just $1 \%$, all the others were higher than 1\%. In 2014, the best 5 hospitals scored between [6.1-4.0\%]; the worst 5 hospitals between [1.1$1.0 \%]$. Seventeen (of 52) hospitals (32,7\%) had a liquidity ratio above $2 \%$. Comparing the number of hospital beds for the 10 best $(491+/-194)$ and 10 worst $(257+/-65)$ performing hospitals, there is a highly significant difference: better performing hospitals had more hospital beds $(p=0.002)$.

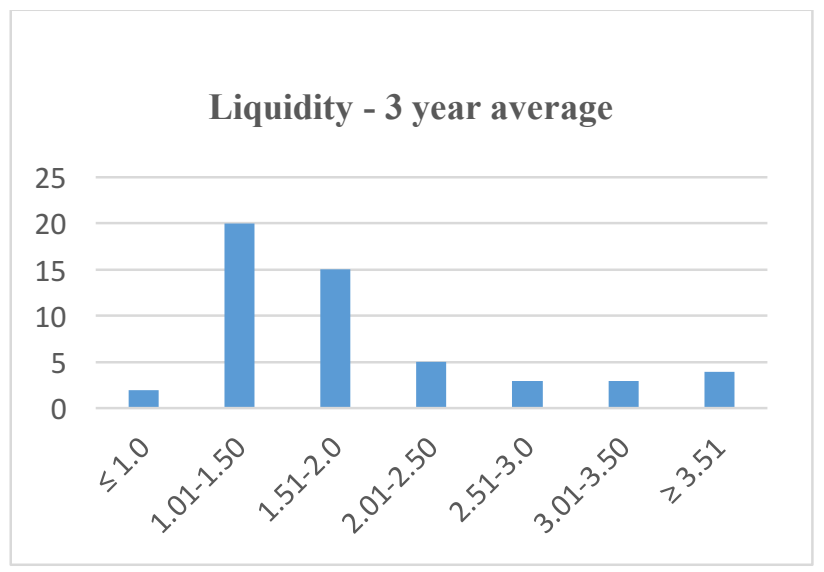

Continuity (investments). Does the hospital continue to invest? We look at the value of infrastructure, medical equipment and other material assets at the end of the book year and compare this against the depreciation value. A ratio of $100 \%$ indicates that all material is brand new and not yet depreciated. A score of $0 \%$ means that all infrastructure and material are old and that no new investments have been made.

The average 3-year continuity of 45 Flemish hospitals was $49.68 \%$ (SD 10.12\%). The range varied from $30 \%$ to $80 \%$. Thirty seven (of 45 ) hospitals $(82.2 \%$ ) had a continuity rate above the 
$40 \%$ threshold. In 2014 , the top 5 hospitals had a continuity between [65-86\%]. The 5 poorest performing hospitals scored between [30-38\%]. The best performing hospital had a continuity of $86 \%$. Ten hospitals (22.2\%) had a continuity above $60 \%$, 46 hospitals were above $40 \%$ (indicating that they invest more than 1.5 times the amount that they depreciate). There is no statistical difference in the number of hospital beds of those hospitals with a continuity index $\leq 40$ and those $\geq 55$.

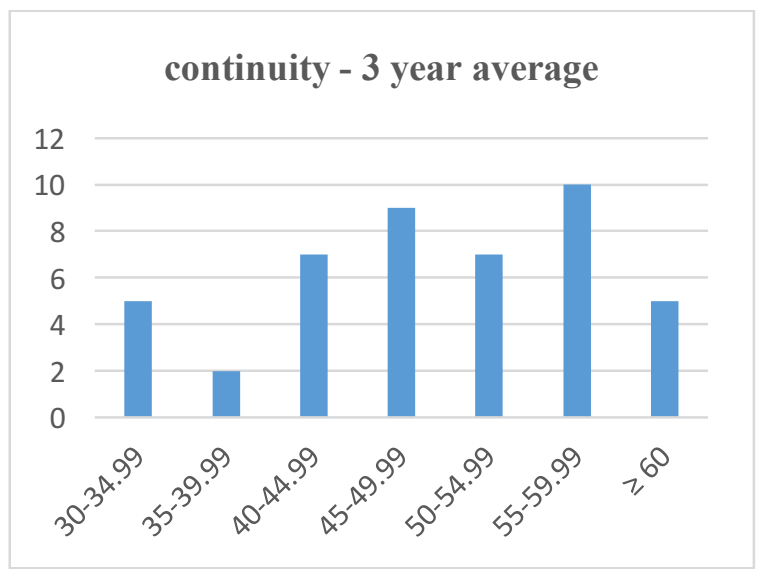

For further analysis, we made an 'overall financial score' for every hospital. Over the period 2012-14, 15 hospitals (28.8\%) had a low overall financial score (scoring 0-2 times above average on the 5 items), 10 had an intermediate score ( 3 times above average), and 27 had a good overall financial score (4-5 times above average).

\section{Standard of (published) quality of Flemish non-university hospitals}

Quality scores range from 0 to 19 (18 scoring items plus accreditation status). The average score for all hospitals was 6.9 (SD 4.1). Fourteen hospitals (26.9\%) score 'fairly poor' ( $\leq 3$ times above Flemish average for that topic) on measured/published quality parameters, the remaining hospitals are somewhat evenly distributed along the quality gradient with 2 hospitals scoring 'zero' and 8 hospitals scoring 'rather well' (12-15 times above Flemish average). No one general hospital 
had a (near) perfect quality score. Size of the hospital (number of hospital beds) is statistically of no influence on the rating of measured quality topics when hospitals that scored $\geq 10$ are compared with those scoring $\leq 5(\mathrm{p}=0.24)$. When those hospitals that score $0-3$ are compared with those scoring $12-15$, then larger hospitals significantly deliver higher measurable quality $(\mathrm{p}=0.05)$.

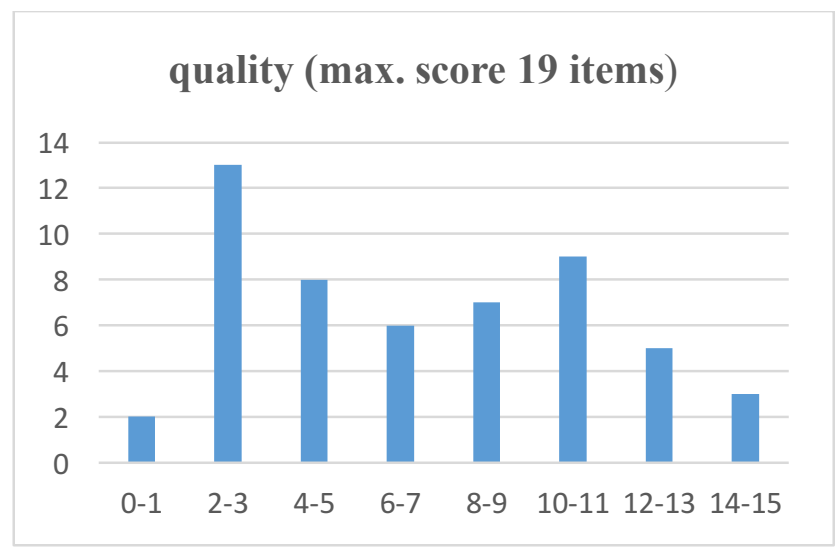

Only 5 of the 52 general hospitals in Flanders and that were studied are formally accredited (3 times JCI, 2 times NIAZ - status May 2016). Accredited hospitals' average quality score (11 +/$2.5)$ is significantly higher than that of non-accredited hospitals $(6.5+/-4.0)(\mathrm{p}<0.01)$.

There was some tendency that hospitals that had a higher continuity index, also had a higher quality score with a p-value (0.085) approaching significance.

We also looked at 'quality' in a broader sense: what does the hospital gives back to the community. Of the 52 general hospitals, 15 hospitals participated in some form of community work (mainly supporting medical NGO's or fostering a hospital in Africa).

\section{Correlation between financial performance or investments and published standards of quality of care}

For every financial score ( 0 to 5 ) or continuity range the average quality score and standard deviation is calculated for the aggregate of all hospitals in that class. 


\begin{tabular}{|l|l|l|l|l|l|}
\hline Financial score (0-5) & $0-1$ & 2 & 3 & 4 & 5 \\
\hline Quality performance & $6.6+/-3.0$ & $5.4+/-3.6$ & $7.1+/-4.4$ & $6.8+/-4.5$ & $9.5+/-4.1$ \\
\hline
\end{tabular}

\begin{tabular}{|l|l|l|l|l|l|l|l|}
\hline $\begin{array}{l}\text { Continuity } \\
(\%)\end{array}$ & $30-34.99$ & $35-39.99$ & $40-44.99$ & $45-49.99$ & $50-54.99$ & $55-59.99$ & $\geq 60$ \\
\hline $\begin{array}{l}\text { Quality } \\
\text { performance }\end{array}$ & $3.8+/-3.6$ & $8.0+/-2.8$ & $8.9+/-3.4$ & $7.2+/-3.6$ & $7.6+/-5.7$ & $6.7+/-4.8$ & $6.0+/-3.8$ \\
\hline
\end{tabular}

Chart 1 depicts the correlation between financial score and quality performance. The actual score on quality performance is plotted against financial score. We added a linear regression to examine to what extent this statistical model approximates the actual data plot trying to examine to what extent we find a statistical correlation between financial score and quality performance. From the calculation of the determination coefficient $\left(\mathrm{R}^{2}=0,0767\right)$ we deduct a slightly positive correlation which however is not statistically significant $(r=0,0277)$. The regression model that assumes a positive correlation between financial score and quality performance only explains a small (insignificant) proportion of the variance in the actual data signalling there is no statistically significant association between financial performance and reported quality. Likewise, chart 2 depicts the correlation between continuity and quality score. The determination coefficient $\mathrm{R}^{2}$ here is 0.007 indicating that there is absolutely no 'goodness of fit' in the statistical model between continuity (investments) and quality performance. 


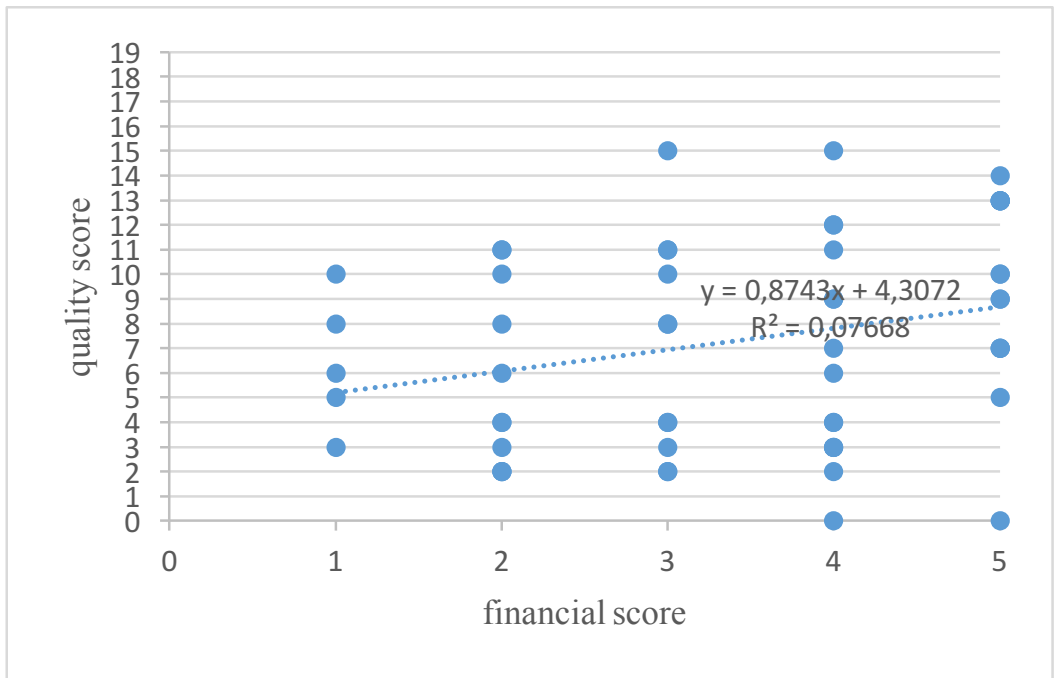

chart 1

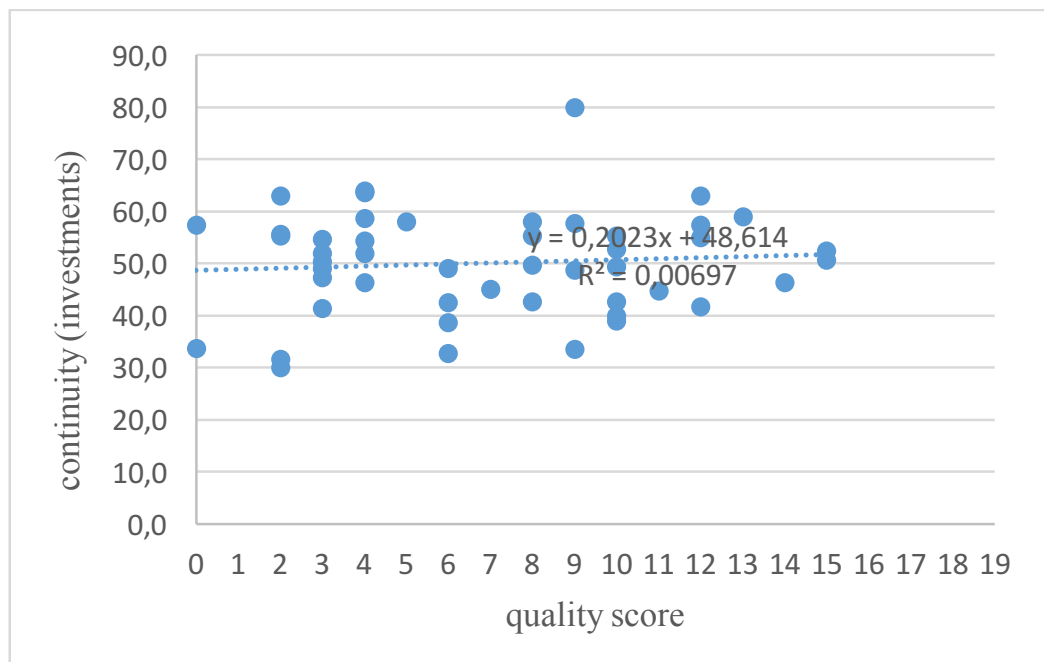

chart 2

Our study sample contains some very interesting outliers. Two hospitals scored 0 on quality performance but had excellent financial performance (financial score 4 or 5). One hospital scored high on quality but had a very poor financial performance. The hospital with the largest revenue and profit scored poor on quality.

We can answer our RQ's as follows:

RQ 1: the financial situation of Flemish non-university hospitals over the period 2012-14 is worrisome. One in 4 hospitals is in a danger zone and half of the hospitals might come into financial 
problems when they encounter a financial upset. A positive note is that they do continue to invest in medical infrastructure, regardless of hospital size. The number of hospital beds may be a moderator to explain net profit and liquidity. The level of quality performance varies broadly amongst Flemish general hospitals using published quality measures. A significant number of hospitals (26.9\%) currently (2014) have poor quality results. No hospital is able to attain a (near)perfect quality score. Accredited and larger hospitals score significantly better on quality performance.

RQ 2: to date (2014), there is no correlation between financial performance or investments and measurable quality of care amongst Flemish general hospitals.

It can be critiqued for quality indicator measures that the sum of the 19 measurements is no proxy for the overall quality of that hospital. For clinical practice, at this time, only breast cancer is considered. When new indicators become available in the near future (particularly in the fields of cardiology, childbirth, hip surgery, stroke care, ...), the sum of the various items however may start to better reflect the overall situation. Likewise, many Flemish hospitals are still in the early stage of publicly reporting quality. But public pressure and potential financial reward are two of the most important methods that have been proposed to close persistent gaps in the quality and safety of healthcare (Lindenauer et al., 2007) and will stimulate hospitals to join the quality reporting movement.

\section{Lessons for Practice}

How can Flemish general hospitals join the value movement? One the one hand, financial performance of Flemish general hospitals needs to be monitored closely and longitudinally since many of them were in the period 2012-14 in a danger zone. In Flanders, during the past 10 years, 
a quarter of the general hospitals disappeared to exist. Similarly, many hospital need to improve their quality of care standards. Actually, measured and published quality standards are, on average, mediocre. To date (2014), no correlation exists between hospital financial and quality performance in Flanders. Good quality can go hand-in-hand with poor financial performance and vice versa. The early stage of publishing quality indicators by hospitals in Flanders might explain the disconnect at this time, but longitudinal follow-up is necessary. Thus there remain great policy and implementation challenges if Flemish general hospitals want to make a shift from a volume-driven towards a patient-centred, value-driven financing model. It will require from many hospital administrators, but also care insurers and healthcare providers a leap of faith to turn their mindset away from short term financial gain thinking towards value-based healthcare delivery at mid- and long term.

\section{Contributions to Theory}

Value-driven healthcare financing. The new value paradigm in healthcare dictates that creation of value for patients should determine the rewards for all other actors in the system (Porter, 2010). One important aspect in this value theory is the assumed "quality $\rightarrow$ financial reward" relationship since, according to the theory, delivering high quality care (that is patient value) would result in realizing financial gains or incentives. Our research provides some evidence that this relationship may either not exist in the early phase of the "volume-to-value transition" in general hospitals (in Flanders) and that thus financial reward lacks behind realizing patient value improvements. The determination of the length of this gap period has important implications for hospital strategy since it may determine a period of financial uncertainty in a context where many hospitals are already in a precarious financial situation. Another conclusion could be that the relationship quality/financial reward is not necessarily a straight forward one. In our study, size of 
the hospital (e.g. number of hospital beds) could be a moderator in explaining in part the quality/financial reward relationship (larger hospitals may realize more effective or efficient quality improvements that result in a lower cost to achieve a better outcome). The search for other potential mediators/moderators (e.g. fraction or type of value-reimbursed interventions, size of the value bonus, subsidies/incentives for promoting quality improvement, ...) warrant further research.

\section{Appendix on Method}

\section{Financial parameters}

Financial data of the 52 Flemish general, non-university hospitals were obtained from the Belfius-MAHA (model for automatic hospital analysis) study (see: http://www.tijd.be/service/ziekenhuizen). These data are made publicly available since 2012. Data on the financial situation of all the hospitals is compelled by studying the balance sheets (as they are submitted to 'balance sheet repertory' of the Belgian National Bank). Five financial and investment parameters were used in this study: profitability, solvability, liquidity, continuity, and net profit. If a hospital scored above the pre-defined cut-off value for that particular parameter, it was awarded one point for that parameter. In that way, hospitals can receive a score between 0 and 5 for their 'overall financial performance'.

For the parameters profitability, solvability, liquidity, and net profit, we had data on $100 \%$ of the hospitals, for the item continuity for $86.5 \%$ of the hospitals in Flanders. Since there were complete data available for almost every hospital, there is a good generalization for the situation in Flanders. 


\section{Quality parameters}

Hospitals in Flanders measure quality; some measures they do voluntarily, others are compulsory. Data on quality issues were obtained from the website www.zorgkwaliteit.be. This is a public forum initiated by the Flemish Government ('Vlaams Indicatorenproject voor Patiënten en Professionals - VIP') in collaboration with the health care sector ('Vlaanderen in Zorg'). Quality issues are currently scored on 3 dimensions: breast cancer care, patient satisfaction, and hospital-wide. The following specific items were measured and published:

1. Breast cancer

a. In what percentage of patients with breast cancer was hormone sensitivity and/or HER2-status determined prior to the start of chemotherapy, hormone therapy or a treatment with trastuzumab?

b. In what percentage of patients with breast cancer was a cell or tissue examination of the tumour performed prior to breast surgery?

c. In what percentage of patients in an early disease stage of breast cancer (cStage I, II or III) a mammography and/or breast echography was performed in the 3 months prior to breast surgery?

d. What percentage of patients had a multidisciplinary evaluation?

e. What percentage of patients with breast cancer in early stage (cStage I and II) was treated with breast-saving surgery (= tumorectomie)?

f. What percentage of patients was treated with radiotherapy after breast-saving surgery (= tumorectomie)?

g. What percentage of patients with metastasized breast cancer was treated with chemotherapy or hormonal therapy? 
h. What percentage of patients is still alive 5 years after being diagnosed with breast cancer? For this indicator, all causes of death are considered, not just cancer.

i. What percentage of patients is still alive 5 years after being diagnosed with breast cancer, taking into account age of the patient and extensiveness of the tumour. For this indicator, all causes of death are considered, not just cancer.

j. What percentage of patients diagnosed with breast cancer is still alive 5 years after diagnosis if we only consider cancer as cause of death?

2. Patient experiences

a. What percentage of the criteria related to patient information was met on the hospital website? (that information that was relevant and easy to find for patients)

b. What percentage of patients would "surely" recommend this hospital to friends and family? (patients were given the following choices: definitely not, probably not, probably, surely).

c. What percentage of patients gave a 9/10 or 10/10 to this hospital? (patients can score between $0 / 10$ and $10 / 10)$.

3. Hospital-wide

a. What percentage of people involved in patient care meets the minimal requirements for good hand hygiene?

b. What percentage of medication prescriptions is complete? Is all information for correct delivery. Is all information that is necessary for the correct delivery of all of the medication on the prescription by the pharmacist present?

c. What percentage of patients that were checked carried an identification tag with all necessary and correct elements? 
d. Checklist safe surgery 1 : What percentage of the 22 checks were actually carried out prior, during, or after a surgical procedure?

e. Checklist safe surgery 2: What percentage of foreseen checks were actually carried out prior, during, or after a surgical procedure?

We ourselves additionally measured the following items via public forums.

4. Accreditation: we assessed the accreditation status via information obtained from the JCI and NIAZ (= accreditation bodies) websites.

5. 'Community contribution': regional or international participation (as communicated on the hospital's website) in project with a broader societal benefit. This item was assessed by 3 independent observers who examined every hospital's website.

\section{References}

Albright, H., \& Feeley, T. 2011. A Cancer Center Puts the New Approach to Work. Harvard Business Review, 61-62.

Berwick, D.M. 2008. The Triple Aim: Care, Health, and Cost. Health Affairs, 27(3), 759-769.

Brown, W. 2005. Exploring the Association Between Board and Organizational Performance in Nonprofit Organizations. Nonprofit Management and Leadership, 15(3), 317-339.

Dong, G. N. 2015. Performing Well in Financial Management and Quality of Care: Evidence from Hospital Process Measures for Treatment of Cardiovascular Disease. BMC Health Services Research, 15, 45. 
Eeckloo, K., Van Herck, G., Van Hulle, C., \& Vleugels, A. 2004. From Corporate Governance To Hospital Governance: Authority, Transparency and Accountability of Belgian Non-profit Hospitals' Board and Management. Health Policy, 68(1), 1-15.

Forbes, D. 1998. Measuring the Unmeasurable: Empirical Studies of Nonprofit Organization Effectiveness from 1977-1997. Nonprofit and Voluntary Sector Quarterly, 27, 183-202.

Griffith, J., Alexander, J., \& Warden, G. 2002. Measuring Comparative Hospital Performance. Journal of Health Care Management, 47(1), 41-57.

Herman, R., \& Renz, D. 1999. Thesis on Nonprofit Organizational Effectiveness. Nonprofit and Voluntary Sector Quarterly, 28, 107-125.

Hibbard, J. H., Stockard, J., \& Tusler, M. 2003. Does Publicizing Hospital Performance Stimulate Quality Improvement Efforts? Health Affairs, 22(2), 84-94.

Lee, T. H. 2010. Putting the Value Framework to Work. New England Journal of Medicine, $363(26), 2481-2483$.

Lindenauer, P. K., Remus, D., Roman, S., Rothberg, M. B., Benjamin, E. M., Ma, A., \& Bratzler, D. W. 2007. Public Reporting and Pay for Performance in Hospital Quality Improvement. New England Journal of Medicine, 356(5), 486-496.

Marshall M.N., Shekelle P.G., Leatherman S., \& Brook R.H. 2000. The Public Release of Performance Data: What Do We Expect to Gain? A Review of the Evidence. $\boldsymbol{J A M A}$, 283(14), 1866-1874.

Miller, H. D. 2009. From Volume to Value: Better Ways to Pay For Health Care. Health Affairs, 28(5), 1418-1428.

Miller, D. C., Gust, C., Dimick, J.B., Birkmeyer, N., Skimmer, J. \& Birkmeyer, D.B. 2011. Large Variations in Medicare Payments for Surgery Highlight Savings Potential from Bundled Payment Programs. Health Affairs, 30(11), 2107-2111. 
Nguyen, O. K., Halm, E. A., \& Makam, A. N. 2016. Relationship Between Hospital Financial Performance and Publicly Reported Outcomes. Journal of Hospital Medicine, 11(7), 481488.

Pollock, R. 2008. Value-based Health Care: the MD Anderson Experience. Annals of Surgery, $248,510-516$.

Porter, M. E. 2009. A Strategy for Health Care Reform — Toward a Value-Based System. New England Journal of Medicine, 361(2), 109-112.

Porter, M. E. 2010. What Is Value in Health Care? New England Journal of Medicine, 363(26), 2477-2481.

Porter, M. E., \& Guth, C. 2012. Redefining German Health Care: Moving to a Value-Based System. Springer Science \& Business Media.

Porter, M., \& Kaplan R. 2016. How to Pay for Health Care. Harvard Business Review, 94, July/August.

Porter, M., \& Lee, T. 2013. The Strategy That Will Fix Health Care. Harvard Business Review, October.

Shortell, S.M., \& Casalino, L.P. 2008. Health Care Reform Requires Accountable Care Systems. JAMA, 300(1), 95-97.

Tsai, T. C., Jha, A. K., Gawande, A. A., Huckman, R. S., Bloom, N., \& Sadun, R. 2015. Hospital Board and Management Practices are Strongly Related to Hospital Performance on Clinical Quality Metrics. Health Affairs, 34(8), 1304-1311.

Vélez-Gonzalez, H, Pradhan, R, \& Weech-Maldonado, R. 2011. The Role of Non-financial Performance Measures in Predicting Hospital Financial Performance: the Case of For-profit System Hospitals. Journal of Health Care Finance, 38(2), 12-23. 